\title{
EMERGENCY OBSTETRIC HYSTERECTOMY- A STUDY IN TERTIARY CARE CENTRE
}

\author{
Eshu Dixit ${ }^{1}$, Shruti Pathak2, Nootan Chandwaskar³, N. Natu ${ }^{4}$ \\ $12^{\text {nd }}$ Year Postgraduate Student, Department of Obstetrics and Gynaecology, SAIMS, Indore. \\ ${ }^{2} 3^{\text {rd }}$ Year Postgraduate Student, Department of Obstetrics and Gynaecology, SAIMS, Indore. \\ 3 Professor, Department of Obstetrics and Gynaecology, SAIMS, Indore. \\ 4 Professor, Department of Obstetrics and Gynaecology, SAIMS, Indore.
}

\section{ABSTRACT}

\section{BACKGROUND}

Emergency obstetric hysterectomy (EOH) refers to surgical removal of a pregnant uterus or recently pregnant uterus. Many a times, an attempt to control haemorrhage fails and woman's life is saved by compromising her reproductive capability by obstetric hysterectomy. It is usually performed in the face of unrelenting and life-threatening obstetric haemorrhage.

We sought to study cases of obstetric hysterectomy over a period of one year to determine the incidence, indications, maternal complications and use of vasopressor drugs in a teaching institute.

\section{MATERIALS AND METHODS}

We conducted a Retrospective Observational Study over a period of one year from August 2016 to August 2017. A total of five cases of emergency obstetric hysterectomy (EOH) were studied in the Department of Obstetrics and Gynaecology, Sri Aurobindo Institute of Medical Sciences, Indore, Madhya Pradesh.

\section{RESULTS}

The incidence of EOH in our study was 02 per 1500 following vaginal delivery and 02 per 500 following caesarean section. The overall incidence was 05 per 2000 deliveries. Atonic postpartum haemorrhage $(60 \%)$ was the most common indication followed by placenta accreta (20\%) and uterine rupture (20\%). The most frequent sequelae were ICU admissions (45\%) and fever (27\%), while vasopressors were given in $18 \%$ of the total patients studied. There was no maternal death in the study.

\section{CONCLUSION}

A balanced approach to EOH can prove to be life-saving at times when conservative surgical modalities fail and interventional radiology is not immediately available. Our study highlights the place of extirpative surgery in modern obstetrics in the face of rising rates of caesarean section and multiple pregnancies, particularly in urban settings in developing countries.

\section{KEYWORDS}

Retrospective Studies, Obstetric Hysterectomy, Atonic Postpartum Haemorrhage, Caesarean Section.

HOW TO CITE THIS ARTICLE: Dixit E, Pathak S, Chandwaskar N, et al. Emergency obstetric hysterectomy- a study in tertiary care centre. J. Evolution Med. Dent. Sci. 2017;6(90):6282-6285, DOI: 10.14260/jemds/2017/1366

\section{BACKGROUND}

Emergency obstetric hysterectomy (EOH) refers to surgical removal of a pregnant uterus or recently pregnant uterus. Many a times, an attempt to control haemorrhage fails and a woman's life is saved by compromising her reproductive capability by obstetric hysterectomy. It is usually performed in the face of unrelenting and life-threatening obstetric haemorrhage. A near miss event is defined as a woman who nearly died but survived a complication that occurred during pregnancy, childbirth or within 42 days of termination of pregnancy.[1] Conservative methods such as communitybased use of misoprostol, oxytocin in the prefilled autodisable drug delivery systems, condom catheter balloon and non-inflatable anti-shock garments for the management of hypovolemic shock have all been advocated to effectively manage obstetric haemorrhage in low resource settings.[2]

'Financial or Other Competing Interest': None.

Submission 09-10-2017, Peer Review 02-11-2017,

Acceptance 08-11-2017, Published 20-11-2017.

Corresponding Author:

Dr. Shruti Pathak,

GF/19, Scheme No. 54,

Jyoti Hospital, Vijay Nagar,

E-mail: naiveshruti27@gmail.com

DOI: $10.14260 /$ jemds $/ 2017 / 1366$
Advances in interventional radiology have also provided

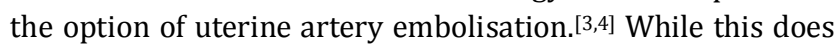
seem encouraging with regard to clinical implications, haemorrhage continues to be the leading individual cause of maternal death worldwide accounting for $27.1 \%$ of deaths as recently as 2014.[5] In this analysis, India and Nigeria together accounted for a third of global maternal deaths.[5] More alarming is the fact that some studies from developed nations are pointing towards an increase in the rate of postpartum haemorrhage.[6] One meta-analysis reported an annual increase of $8 \%$ in the incidence of EOH around the world. ${ }^{[7]}$ Similarly, in spite of advancement in obstetrics, dais handling of obstructed labour and its complications are quite prevalent in rural India. So to prevent massive haemorrhage in ruptured uterus, many times emergency obstetric hysterectomy is considered as the definitive management. Prompt decision making and excellent surgical skills with a speedy intervention are the key component of this life-saving procedure. Early resuscitation, transfusion of blood and blood components helps to improve deteriorating haemodynamic parameters and helps the patient to withstand the surgical procedure and anaesthesia.

\section{MATERIALS AND METHODS}

This was a Retrospective Observational Study of parturient women requiring EOH/ emergency peripartum hysterectomy 
(EPH). We looked at data over a one-year period from August 2016 to August 2017 from the Department of Obstetrics and Gynaecology, Sri Aurobindo Institute of Medical Sciences and Postgraduate Institute, Indore, India.

EPH was defined as hysterectomy performed for haemorrhage unresponsive to other therapeutic interventions, at the time of caesarean section or vaginal delivery or within puerperium. Inclusion criteria included all women who delivered in the hospital between August 2016 and August 2017 after 24 weeks of gestation and who underwent hysterectomy for obstetric indications at the time of delivery or subsequently within the defined period of puerperium (42 days). All women who delivered outside the hospital and were referred for obstetric complications meriting a hysterectomy and fulfilling all the above conditions were also included in the study. Women who delivered before 24 weeks of gestation, undergoing hysterectomy for indications other than obstetric or outside the stipulated time of 42 days post-delivery were excluded from the study. After collecting relevant data from the operation theatre records, each patient's case record was scrutinised with regard to incidence, indications, complications along with the ultimate foeto-maternal outcome and use of vasopressor drugs. Institutional Ethical Committee approval was obtained for the study.

\section{RESULTS}

Incidence of emergency obstetric hysterectomies (EOH) following vaginal delivery and caesarean section. Out of 2000 deliveries, the incidence of obstetric hysterectomy in our study was $0.13 \%$ (02 hysterectomies per 1500 deliveries) following vaginal delivery and $0.60 \%$ (03 hysterectomies per 500 deliveries) following caesarean section. The overall incidence was $0.25 \%$ (05 hysterectomies per 2,000 deliveries).

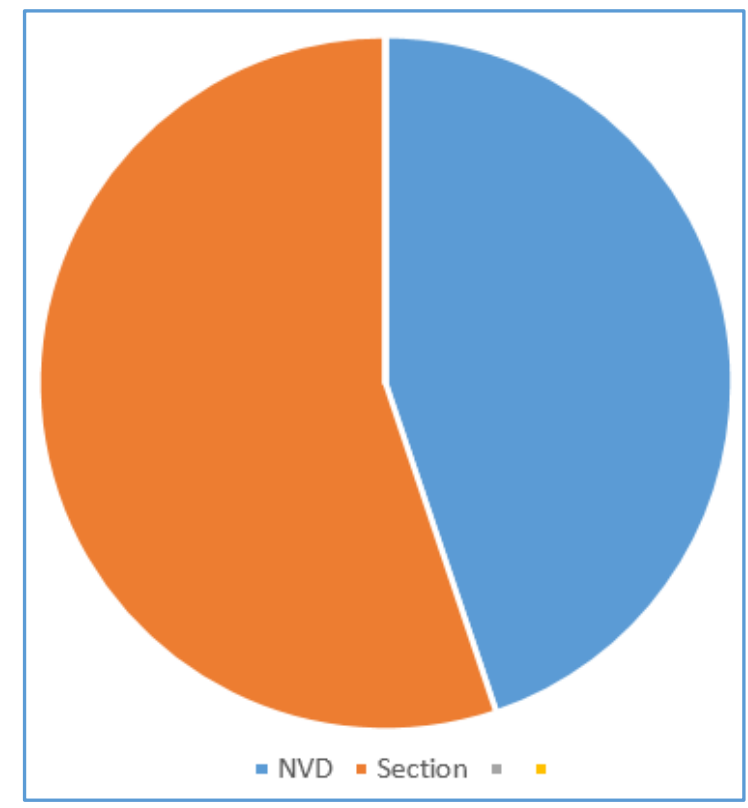

Figure 1. Shows the Association of Caesarean Section with EOH

Of the 05 cases of EOH studied, 3\% of deliveries were institutional, whereas $2 \%$ of patients delivered outside the hospital and were later referred for further management.
Atony, morbidly adherent placenta and uterine rupture were the three chief indications for the procedure [Table 2]. Atonic postpartum haemorrhage was the indication for $\mathrm{EOH}$ in 03 cases.

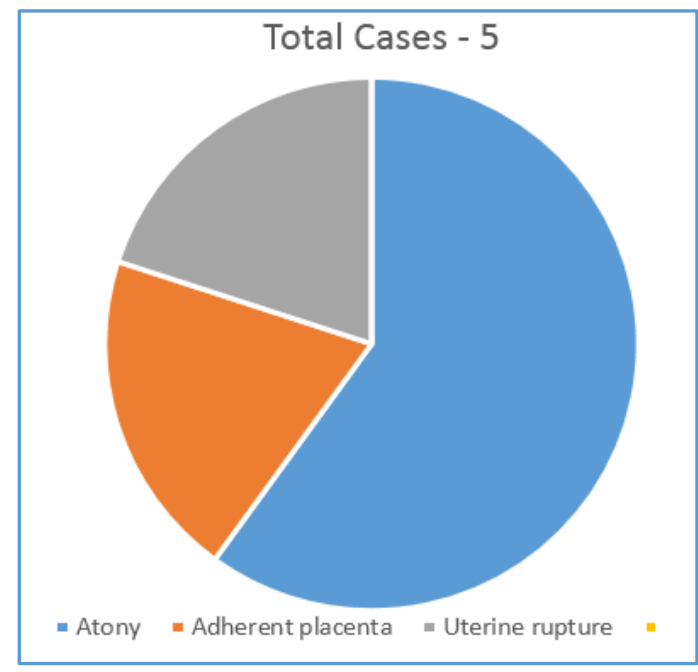

Figure 2. Indications of Obstetric Hysterectomy in the Study

Morbidly adherent placenta was the indication for EOH in 01 case and was associated with more than one caesarean sections previously. More than one factor was associated in many cases, for example one woman had history of two prior caesarean sections.

Uterine rupture led to hysterectomy in 01 instance and was associated with grand multiparity. Of the total number of patients $80 \%$ underwent total hysterectomy, while in $20 \%$ cases subtotal hysterectomy was performed in our study.

\section{Maternal Complications}

Table 3 shows the incidence of foeto-maternal complications. One case experienced resistant hypotension and was managed with single or multiple agent vasopressor drugs as per intensive care unit (ICU) protocols.

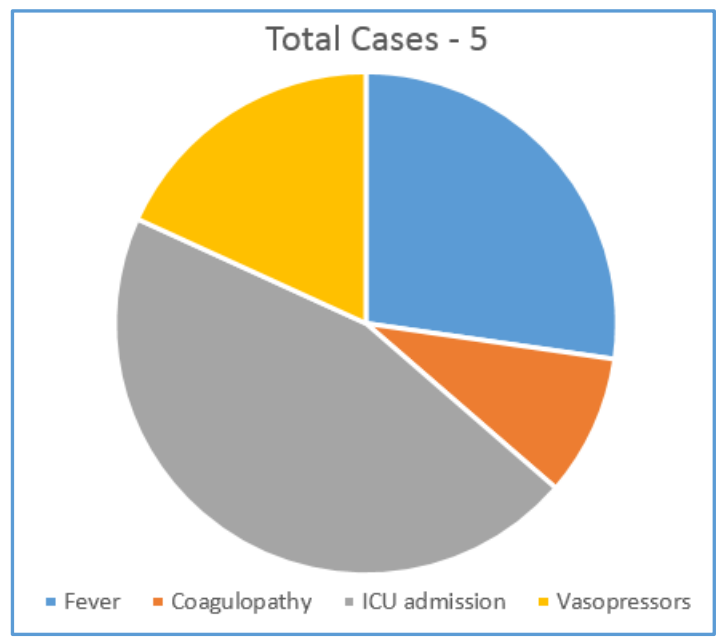

Figure 3. Foeto-Maternal Complications

Dopamine was used as the first-line agent to manage shock. Adrenaline or noradrenaline infusion was added at the discretion of the anaesthetist whenever required. Patients received transfusion of blood and blood products as per requirement. 


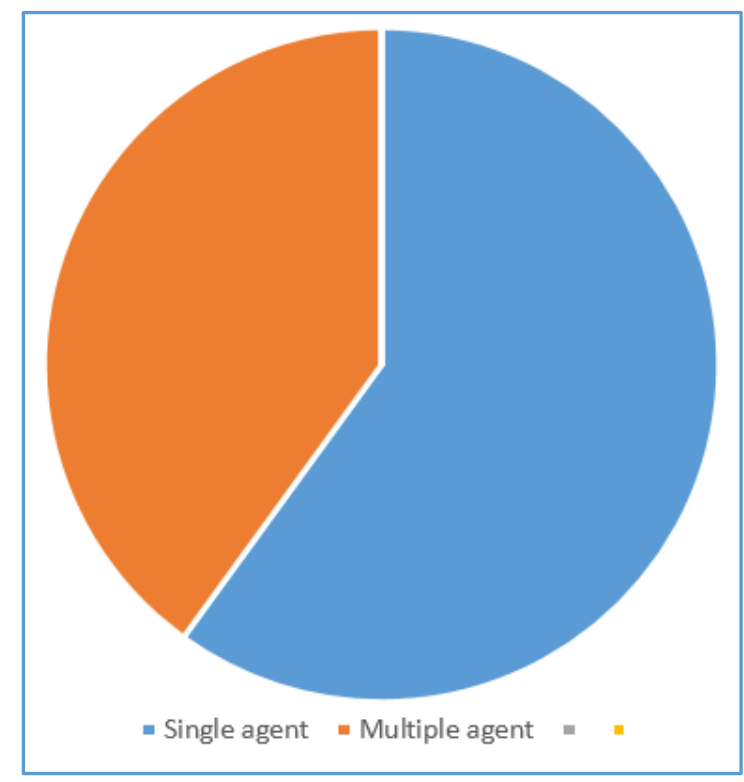

Figure 4. Use of Vasopressors

\section{DISCUSSION}

Obstetric hysterectomy still is an important tool for the obstetrician. Expert and experienced surgeons in this operation can save lives in catastrophic rupture of the uterus or intractable PPH.[8] Storer performed the first caesarean hysterectomy in the United States in 1869.[9] Soon thereafter Porro of Milan described the first caesarean hysterectomy, in which the infant and mother survived. As a mark of honour, the procedure is frequently referred to as the Porro operation. ${ }^{[9]}$ Caesarean hysterectomy traditionally is classified as elective for the management of incidental diseases like cervical intraepithelial neoplasia (CIN) or for the purpose of sterilisation, and in cases of emergency to control intractable haemorrhage. With changes in practice in the light of modern evidence, the former two indications seem to have lost relevance. However, there has been an upsurge in cases of postpartum haemorrhage requiring hysterectomy, ${ }^{[10]}$ primarily due to the changed settings in which postpartum haemorrhage presents itself in modern obstetrics. Despite wider availability of contraceptives and abortion services and reduced family size the world over, there has been a consistent rise in the rates of caesarean section attributable in part to patient preferences and medico-legal implications on medical fraternity. Additionally, advances in anaesthesia, blood bank facilities and intensive care back-up have made it a safer and painless alternative to labour. This has not only given rise to a surge in complications like abnormal placentation and uterine rupture, but also in the incidence of atonic postpartum haemorrhage. This is why EOH has become increasingly relevant in modern obstetric practice. The most common indication of EOH in our study was uterine atony (60\%) followed by morbidly adherent placenta (20\%) and uterine rupture $(20 \%)$. This reflects the situation in most developing countries where atony accounts for the majority of cases of $\mathrm{EOH}$, but also shows a rising contribution of placental causes which is replicating the trend in the developed world. Studies from other tertiary care centres in India,[11] the UK[12] and Turkey[13] also revealed atonic postpartum haemorrhage to be the most common indication for $\mathrm{EOH}$. Complication due to coagulopathy was variable ( $6 \%$ to $37 \%$ ) in all cases of $\mathrm{EOH}$ in various publications. Almost one-fifth of cases (19.6\%) underwent a re-exploration and further surgery to arrest haemorrhage in one study from the UK and $12.5 \%$ of cases in a study from Hong Kong.[11] Incidence of urinary tract injury in studies from the UK, Nigeria,[14] China[15] and another centres from India[11] were $12.2 \%, 3.6 \%, 4.1 \%$ and $7.93 \%$, respectively. Many reports and guidelines have advocated the preference for subtotal hysterectomy over total hysterectomy since it offers the advantage of less blood loss, fewer instances of damage to the urinary tract and takes less time to complete in the face of haemodynamic compromise/ instability. ${ }^{[16,17]}$ However, in cases of morbidly adherent placenta, total hysterectomy may prove more beneficial as removal of the cervix leads to better haemostasis.[18]

\section{CONCLUSION}

Proper antenatal care and early referral can prevent this catastrophic event. Moreover, timely decision, liberal blood transfusion and speedy surgery by an experienced surgeon are important in the management of this life-saving procedure to avoid complications. EOH is a necessary evil in obstetrics. Although, it curtails the future child-bearing potential of the woman, in many cases it saves the life of the mother. Most of its morbidity is attributable to its indications and underlying disorders rather than to the procedure itself. Training postgraduate trainees in this rare skill can prove life-saving in situations where expertise or facilities for newer modalities of management, such as uterine artery embolisation, do not exist or fail. Rising rates of caesarean section and multiple pregnancies are bound to increase the incidence of $\mathrm{EOH}$ in the future.

\section{REFERENCES}

[1] Say L, Souza JP, Pattinson RC, et al. Maternal near miss-towards a standard tool for monitoring quality of maternal health care. Best Pract Res Clin Obstet Gynaecol 2009;23(3):287-96.

[2] Miller S, Lester F, Hensleigh P. Prevention and treatment of postpartum hemorrhage: new advances for low-resource settings. J Midwifery Women's Health 2004;49(4):283-92.

[3] Singhal S, Singh A, Raghunandan C, et al. Uterine artery embolization: exploring new dimensions in obstetric emergencies. Oman Med J 2014;29(3):217-9.

[4] Varghese S, Gokulam N, Al-Abri S. Uterine artery embolization in postpartum hemorrhage: a case report. Oman Med J 2012l;27(2): e033.

[5] Say L, Chou D, Gemmill A, et al. Global causes of maternal death: a WHO systematic analysis. Lancet Glob Health 2014;2(6):e323-e33.

[6] Cameron CA, Roberts CL, Olive EC, et al. Trends in postpartum haemorrhage. Aust N Z J Public Health 2006;30(2):151-6.

[7] Tunçalp 0, Hindin MJ, Souza JP, et al. The prevalence of maternal near miss: a systematic review. BJOG 2012;119(6):653-61.

[8] Devi P, Singh RK, Singh D. Emergency obstetric hysterectomy. J Obstet Gynecol India 2004;54(4): 343-5.

[9] Durfee RB. Evolution of cesarean hysterectomy. Clin Obstet Gynecol 1969;12(3):575-89. 
[10] Joseph KS, Rouleau J, Kramer MS, et al. Investigation of an increase in postpartum haemorrhage in Canada. BJOG 2007;114(6):751-9.

[11] Juneja SK, Tandon P, Mohan B, et al. A change in the management of intractable obstetrical hemorrhage over 15 years in a tertiary care center. Int J Appl Basic Med Res 2014;4(Suppl 1):S17-S9.

[12] Knight M, UKOSS. Peripartum hysterectomy in the UK: management and outcomes of the associated haemorrhage. BJOG 2007;114(11):1380-7.

[13] Tapisiz OL, Altinbas SK, Yirci B, et al. Emergency peripartum hysterectomy in a tertiary hospital in Ankara, Turkey: a 5-year review. Arch Gynecol Obstet 2012;286(5):1131-4.

[14] Abasiattai AM, Umoiyoho AJ, Utuk NM, et al. Emergency peripartum hysterectomy in a tertiary hospital in southern Nigeria.Pan Afr Med J 2013;15:60.
[15] Pradhan M, Shao Y. Emergency peripartum hysterectomy as postpartum hemorrhage treatment: incidence, risk factors and complications. JNMA J Nepal Med Assoc 2014;52(193):668-76.

[16] Greer I, Lang GG, Patel AN, et al. The management of postpartum haemorrhage. Scottish Obstetric Guidelines and Audit Project 1998.

[17] Roopnarinesingh R, Fay L, McKenna P. A 27-year review of obstetric hysterectomy. J Obstet Gynaecol 2003;23(3):252-4.

[18] Langdana F, Geary M, Haw W, et al. Peripartum hysterectomy in the 1990s: any new lessons? J Obstet Gynaecol 2001;21(2):121-3. 